\title{
Desenvolvimento docente para educação remota emergencial: relato da Unicamp
}

\section{Teacher Development for emergency remote teaching and online learning: The Unicamp case study}

Eliana Amaral ${ }^{1}$ (D); Soely A J Polydoro ${ }^{2}$ (D); Marco Antonio A. G. Carvalho ${ }^{3}$ (D)

A pandemia de COVID-19 em 2020 gerou enormes desafios à UNICAMP, exigindo grande esforço da comunidade acadêmica para rápida adaptação, visto que a Unicamp foi a primeira universidade pública a suspender ensino presencial e adotar ensino remoto emergencial (ERE). Alguns pontos principais:

- Disseminação precoce e rápida do ERE facilitada por experiências prévias com recursos digitais e plataformas educacionais de parte dos professores, com apoio dos monitores de graduação e auxiliares de ensino de pós-graduação.

- Rápida resposta para fornecimento de chips, notebooks, desktops e tablets por empréstimo, aos estudantes.

- O sucesso do ERE ocorreu devido a uma comunidade acadêmica engajada, da liderança firme e ágil diante da pandemia, do apoio imediato fornecido para formação em ensino remoto e trocas de experiências, e da confiança no espaço de formação docente e apoio ao ensino virtual previamente construída.

- Percebeu-se a importância da pronta resposta institucional, com apoio ao e do corpo docente e discente, promovendo mudanças nas regras acadêmicas sintonizadas com as decisões administrativos em resposta à pandemia.

\begin{abstract}
RESUMO
O artigo discorre sobre as ações institucionais da Universidade Estadual de Campinas (Unicamp) em relação ao ensino de Graduação em resposta à pandemia e aos esforços anteriores de aprimoramento dos cursos e ao desenvolvimento profissional de seu corpo docente. São apresentados os programas e ações de dois órgãos vinculados à Pró-Reitoria de Graduação, o Espaço de Apoio ao Ensino e Aprendizagem (EA2) e o Grupo Gestor de Tecnologias Educacionais (GGTE). Há um relato inicial sobre os programas em andamento e destaque para a discussão da resposta da Unicamp às condições extraordinárias decorrentes da pandemia Covid-19. São evidenciados os ajustes normativos internos e de órgãos de regulação da educação superior no estado de São Paulo, as atividades formativas e os programas de apoio frente aos desafios do ERE adotado pela Instituição. Adicionalmente, um retrato do trabalho remoto docente no período da pandemia é apresentado a partir de dois levantamentos realizados internamente, por órgãos distintos. Essa experiência resultou em um enorme aprendizado para a Unicamp, que mostrou rapidez na tomada de decisões e na execução de ações que mitigassem os impactos negativos no ensino e na aprendizagem. Além do adequado funcionamento de suas estruturas de apoio, verificou-se também um forte
\end{abstract}

\footnotetext{
Universidade Estadual de Campinas, Campinas, São Paulo, Brasil.

${ }_{1}^{1}$ Professora-Titular de Obstetrícia

Pró-Reitora de Graduação

2 Doutora em Educação

Professora na Faculdade de Educação, Unicamp

${ }^{3}$ Doutor em Engenharia Elétrica

Livre Docente
} 
engajamento de seus docentes, colaboradores e estudantes no prosseguimento das atividades da Unicamp no formato remoto por meio do uso de recursos digitais.

Palavras-chave: Educação superior; Docência; Ensino online; Formação profissional; Tecnologia da informação e comunicação.

\section{INTRODUÇÃO}

Após 11 meses da pandemia do coronavírus, declarada pela Organização Mundial de Saúde (OMS) no dia 12 de março de 2020, vivemos ainda uma crescente propagação do vírus, altos índices de ocupação hospitalar, com mais de dois milhões de óbitos no mundo e o Brasil já tendo superado 240 mil mortes. Sabemos, que para além da crise sanitária e da saúde, vivemos crises de natureza econômica, social e política, exacerbando desigualdades conhecidas e criando novas. Assistimos efeito ainda mais perverso de acordo com a condição financeira, social, psicológica, de gênero, idade, etnia, raça, ocupação, dentre outras. ${ }^{1,2}$ Ao mesmo tempo, vivemos também o início da vacinação contra Covid-19 no Brasil, com a expectativa de que ela possa ser ampliada para toda a população, com priorização para o segmento educacional, em um futuro próximo.

Imediatamente, e logo na segunda semana letiva do primeiro semestre de 2020, a Universidade Estadual de Campinas (Unicamp) decidiu pela suspensão das atividades presenciais e adoção do ensino remoto emergencial (GR-024/2020). Para isso, precisou assumir formas inéditas de atuação, com reorganização dos processos de trabalho e modo de atuar na graduação. O ambiente digital, até então presente como complementar, passou a compor o espaço exclusivo de encontro e de mediação de professores e estudantes no processo de ensino-aprendizagem. Isso impactou de modo profundo todos os aspectos da vida acadêmica, acelerando, em curto intervalo de tempo, o processo de adoção de estratégias educacionais com recursos digitais.

Com a necessária interrupção das atividades presenciais da graduação, muitas inquietações, dificuldades, ansiedades, atingiram de modo desigual a comunidade universitária, intensificando vulnerabilidades existentes, especialmente quanto ao acesso à internet ou equipamentos. Mas tam- bém, oportunizou relevantes reflexões, aprendizagens, descobertas e inovações.

Uma série de deliberações da Câmara de Ensino, Pesquisa e Extensão (CEPE/Unicamp) definiram ajustes nas normas acadêmicas e processos de funcionamento excepcional para o Ensino Remoto Emergencial (ERE), buscando garantir o menor prejuízo acadêmico possível. ${ }^{3}$ Tais documentos se alinham com as normativas do Ministério da Educação (MEC) e do Conselho Estadual de Educação de São Paulo (CEE-SP) para o período da pandemia.

O ano marcado por incertezas exigiu que as definições de apoio à comunidade universitária ocorressem de forma rápida, com os necessários ajustes ao longo do tempo, buscando uma ação sistêmica e orgânica. ${ }^{3} \mathrm{O}$ ambiente universitário, acostumado a longos planejamentos, detalhados cronogramas e protocolos, passou a conviver com um contexto de muitas incertezas. A suspensão das atividades presenciais foi prorrogada por cinco vezes, até que em junho definiu-se pela suspensão por prazo indeterminado (Resolução GR-072/2020).

Ao final dos seis primeiros meses de suspensão das atividades presenciais na Unicamp, ao apresentar um panorama dos grandes desafios vivenciados pela instituição, o reitor professor Marcelo Knobel destacou a capacidade e o engajamento da comunidade na reinvenção da Universidade.

"A situação é grave, mas esta não é uma mensagem pessimista nem deve haver nela nenhum sinal de desânimo e resignação. Pelo contrário, se seguimos fortes até aqui, certamente teremos energia e união para superar os obstáculos que estão por vir, graças ao enorme talento e habilidade de inovar de nossos professores, funcionários, alunos e parceiros. E graças também ao comprometimento de todos na defesa do futuro da universidade pública, gratuita e de qualidade. ${ }^{1 "}$

Este artigo reflete um recorte neste complexo cenário, ao focalizar a formação e atuação docente na migração do ensino presencial para o ERE, mediante apoio do Espaço de Apoio ao Ensino e Aprendizagem $[E A]^{2}$ e do Grupo Gestor de Tec-

(https://www.unicamp.br/unicamp/noticias/2020/09/08/em-carta-reitor-faz-balancodos-seis-meses-de-atividades-nao-presenciais) 
nologias Educacionais (GGTE). Esta reconfiguração no funcionamento da graduação permitiu a continuidade na formação dos estudantes de 69 cursos vinculados às áreas de Ciências Humanas; Artes; Ciências Biológicas e Profissões de Saúde e Exatas; e tecnológicas e da Terra, sediados nos campi de Campinas, Limeira e Piracicaba da Unicamp.

Nestes cursos atuam aproximadamente dois mil docentes e totalizam cerca de 20.000 estudantes, que estiveram envolvidos em mais de oito mil disciplinas no primeiro e segundo semestres de 2020. As ações de apoio também foram extensivas aos programas de pós-graduação, que contavam com uma comunidade discente de pouco mais de 16 mil pós-graduandos, vinculados aos 155 cursos de Mestrado Profissional, Mestrado Acadêmico e Doutorado Acadêmico da Unicamp.

A seguir, apresentam-se as políticas e ações da Unicamp relacionadas à formação de seu corpo docente antes e durante a pandemia de Covid-19, com especial ênfase a esta última. A resposta da Unicamp frente ao desafio de atuar na forma do ERE no primeiro ano da pandemia foi enfatizada na sequência. E, finalmente, o conhecimento do perfil dos docentes é balizado em dois levantamentos internos realizados entre maio e julho de 2020, o que permitiu identificar potencialidades e fragilidades do trabalho remoto.

\section{FORMAÇÃO DOCENTE NA UNICAMP - O QUE ERA FEITO ANTES DA PAN- DEMIA}

O [EA $]^{2}$ é um órgão da Pró-Reitoria de Graduação da Unicamp, criado em março de 2010, que visa ao aprimoramento da qualidade do ensino de graduação em nossa universidade por meio do desenvolvimento profissional docente e renovação dos projetos pedagógicos dos cursos. Como reiterado pela literatura, é preciso romper com a concepção de que a competência científica e experiência educacional prévia sejam suficientes para a atuação dos docentes no ensino superior. $4,5,6,7,8$

Nesta perspectiva, são as atribuições do $[E A]^{2}$ : oferecer assessoria técnico-pedagógica aos docentes; oferecer experiências formativas para o desenvolvimento profissional docente; promover e divulgar eventos nas áreas da peda- gogia do ensino superior, aprendizagem, avaliação, projetos político pedagógicos e outros que interessem à qualificação permanente do corpo docente; colaborar com a implementação e normatização dos processos de avaliação do ensino e aprendizado; implementar programas de valorização da atividade docente; identificar, divulgar e assessorar docentes no desenvolvimento projetos de inovação no ensino (Resolução GR-013/2010).

Por meio do desenvolvimento de diferentes programas e ações ligados ao processo de ensino -aprendizagem e construção da identidade e profissionalidade do professor universitário, são oferecidos apoio às coordenações de curso em termos de seus projetos pedagógicos e desenvolvimento curricular (Projeto Estratégico RenovaGrad). Organizam-se cursos, oficinas e palestras voltados para o planejamento de ensino, estratégias de ensino-aprendizagem, tecnologias educacionais e recursos educacionais inovadores, aprendizagem ativa, promoção do engajamento dos estudantes e processo de avaliação educacional (GraduAção). Realizam-se edições do programa Acolhimento aos novos docentes; curso de formação para estudantes da pós-graduação em estágio docente (PED+); assessoria pedagógica e para produção de pesquisa sobre o ensino; divulgação de conhecimento científico sobre inovações curriculares e pedagogia universitária (Acervo didático-pedagógico), dentre outros (https://www.ea2.unicamp.br/).

No âmbito do GGTE, órgão subordinado originalmente às Pró-reitorias de Graduação e Pós-Graduação, criado em 2009 (Resolução GR 34/2009 e retificado pela Resolução GR 15/2010) também já eram desenvolvidas ações com o objetivo de promover e apoiar ações institucionais de desenvolvimento de tecnologias educacionais e de ensino digital na graduação, pós-graduação e extensão universitária (https://ggte.unicamp.br/ wp/). Além da gestão dos ambientes virtuais de aprendizagem (AVA), são desenvolvidos programas de formação para divulgar a importância dos recursos de Tecnologia da Informação e Comunicação (TIC) no ensino e aprendizagem e sobre o uso das plataformas eletrônicas educacionais, realização de provas online, produção de vídeo-aulas e podcasts. O envolvimento do corpo docente em tais iniciativas vinha sendo fomentado via editais de apoio, disponibilização de estúdio de gra- 
vação multimídia com apoio técnico, incentivo ao desenvolvimento de MOOC, helpdesk e eventos.

Especificamente sobre os AVAs, a Unicamp já os disponibilizava há mais de duas décadas, quando desenvolveu e implantou o TelEduc. No momento da suspensão das atividades presenciais, os professores contavam com as plataformas Moodle ${ }^{T M}$, Suite Google ${ }^{T M}$ e Office 365. Todas as disciplinas estavam disponíveis no Moodle ${ }^{T M} \mathrm{e}$ no Google Classroom ${ }^{\mathrm{TM}}$ (GCR) e o professor poderia habilitar aquele que melhor atendia seus objetivos educacionais. Apesar das múltiplas funcionalidades dos ambientes, o uso até então mais frequente referia-se ao compartilhamento de materiais, comunicação por email institucional, realização de exercícios e entrega de tarefas. A exploração dos recursos síncronos era muito restrita e uma minoria dos docentes usava a funcionalidade de avaliação, que ocorria, na maior parte das vezes, presencialmente nos laboratórios de informática das Unidades Acadêmicas.

Tais iniciativas anteriores à situação de pandemia colaboraram de modo relevante para o desenvolvimento do ERE. Como será visto a seguir, foram elaboradas normativas institucionais e ações de apoio ao docente que pudessem dar orientação em um contexto tão complexo e aberto.

\section{RESPOSTA DA UNICAMP À COVID-19 NO ENSINO}

O contexto impôs uma resposta de grande abrangência, envolvendo diferentes iniciativas e órgãos da universidade. Algumas atividades foram definidas como essenciais e precisaram da reorganização para esquemas especiais de trabaIho presencial e remoto. Muitos órgãos e serviços se adaptaram para garantir o apoio à permanência do estudante, como o Serviço de Apoio ao Estudante (SAE), Serviço de Serviço de Assistência Psicológica e Psiquiátrica (SAPPE), Centro de Saúde da Comunidade (CECOM), Restaurante Universitário (RU), Moradia Estudantil (PME), Sistema de Bibliotecas da Unicamp (SBU), Diretoria Acadêmica (DAC), Diretoria Geral da Administração (DGA) e Diretoria Executiva de Direitos Humanos (DEDH), dentre outros. Houve um grande esforço Institucional para disponibilizar equipamentos e acesso à Internet, e manter as bolsas acadêmicas e de cunho social, alimentação, acolhimento e atendimento acadêmico, social, psicológico e médico. ${ }^{3}$

A migração para o trabalho remoto foi total para os colaboradores do [EA $]^{2}$ e GGTE, tendo inclusive sido interrompidas as gravações em estúdio. As atividades previstas para o semestre foram reprogramadas de forma a cumprir seus objetivos originais e mitigar as amplas dificuldades para e com a implantação do ERE. Devido às interseções e ações ampliadas do [EA] ${ }^{2}$ e GGTE, foram necessárias participações em diferentes Grupos de Trabalhos e comissões de proposição de gestão acadêmica da situação. Na Figura 1 são elencadas as principais referências quanto à pandemia e ajustes normativos dos órgãos reguladores, além das ações centrais desenvolvidas na Unicamp quanto ao apoio ao docente 


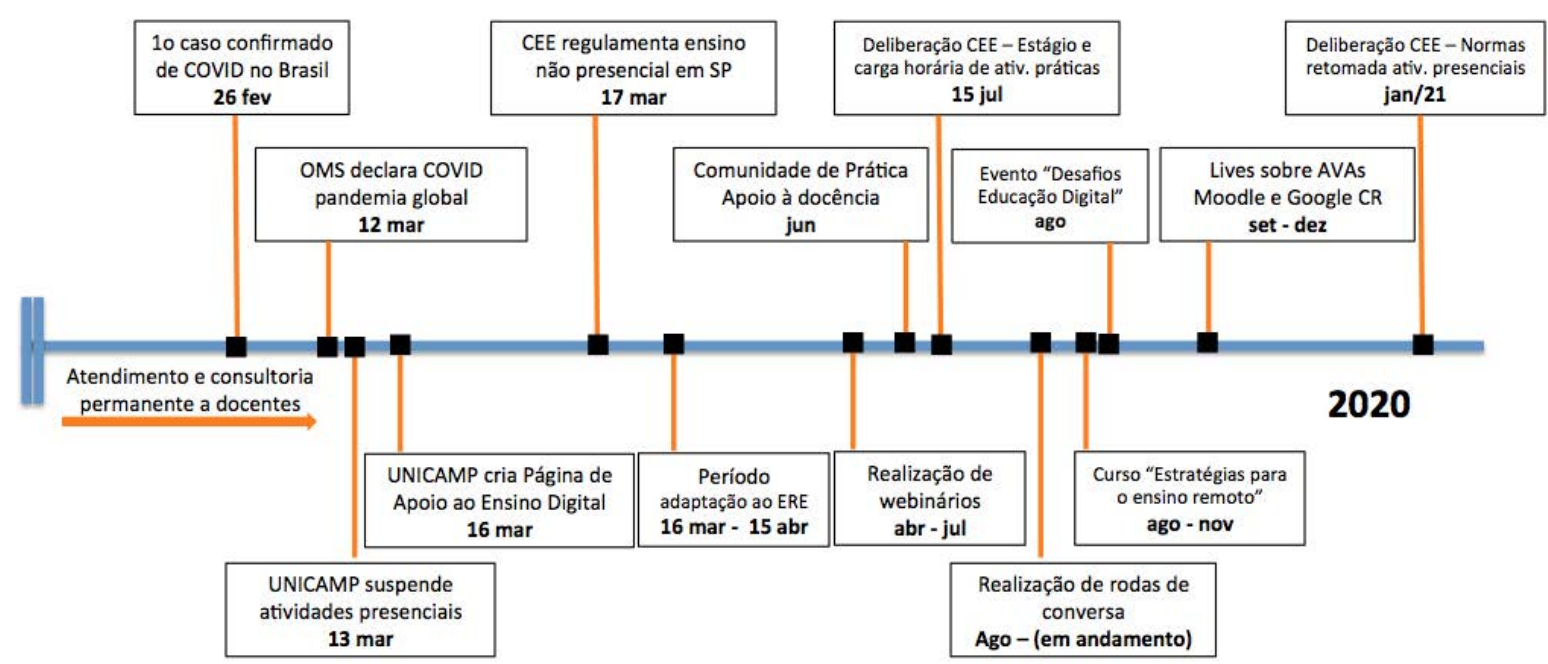

Figura 1: Linha do tempo - Principais ações do $[E A]^{2}$ e GGTE como resposta à pandemia Covid-19

Como já anunciado neste artigo, a Unicamp adotou o termo ERE, visando diferenciar o processo de ensino aprendizagem do momento em comparação ao ensino a distância e, representar as circunstâncias excepcionais do processo de ensino-aprendizagem na pandemia. ${ }^{9} \mathrm{O}$ ensino a distância é planejado com esse fim, dando ênfase aos momentos assíncronos com aulas gravadas (normalmente em estúdios e com apoio técnico para gravação e edição), havendo uma clara opção pela modalidade por parte da instituição e estudantes, dentre outras características. No ERE são usados os recursos previamente existentes, articuladas em um planejamento de curto prazo e aprimorados em processo, envolvem momentos assíncronos, mas associado à mediação síncrona, em tempo real, por meio de plataformas de videoconferências que garantam maior proximidade e interação quasi-presencial com os estudantes, algo essencial na situação da pandemia. 9,10,11

A realização de ações específicas de apoio aos professores no ERE já estava prevista desde a publicação da normativa interna que suspendeu as atividades presenciais. 0 prazo de até um mês para migração das atividades para o espaço digital possibilitou, minimamente, que docentes pudessem planejar e produzir materiais didáticos específicos para o ambiente virtual. A Unicamp optou por não definir um modelo pedagógico para o ERE, mas apresentou considerações e orientações sobre a modelagem de unidades curriculares usando recursos TIC, as quais foram disponibilizadas na página de Apoio ao Ensino Digital (https:// www.ea2.unicamp.br/ensino-digital-2/). Esta página eletrônica, detalhada a seguir, foi colocada no ar de forma célere (Figura 1), como forma de prontamente mediar o suporte aos professores e gestores acadêmicos.

$\mathrm{O}[\mathrm{EA}]^{2}$, focalizando especialmente a formação docente para as exigências do momento e promovendo compartilhamento de experiências, e o GGTE, dando apoio ao uso das ferramentas e recursos tecnológicos/digitais, atuaram de forma unificada, visando a migração às condições impostas e a difusão de boas práticas neste processo de ensino-aprendizagem, promovendo partilha e formação de vínculos. A seguir indicamos frentes de apoio adotadas no ano de 2020, que apesar de organizadas em tópicos separados, são intrinsecamente imbricadas em sua realização.

Transição para ERE - ampla e frequente divulgação à comunidade sobre os processos de migração, soluções possíveis e ajustes normativos; otimização da infraestrutura tecnológica para suportar a carga de utilização; maximização de licenças; ampliação do acesso a plataformas virtuais de conteúdo e ebooks (ação em parceria com SBU); apoio às Unidades Acadêmicas na elaboração do plano de ERE, conforme os limites 
impostos pelas circunstâncias e características das disciplinas, com especial atenção às disciplinas práticas e de assistência. Como refere Osório ${ }^{12}$, o ERE "induz a necessidade de relativizar os currículos e programas padronizados, através da abordagem de temáticas mais abertas, recorrendo a metodologias diversificadas, interativas e colaborativas que, quando conseguidas, são valorizadas." (p. 217) Assim, as discussões sobre projeto pedagógico, organização do currículo, papel de cada disciplina, estratégias de ensino e aprendizagem passaram a dominar as reuniões dos cursos.

Formação da equipe - as equipes do $[E A]^{2}$ e GGTE também tiveram que percorrer um caminho em parte desconhecido, associada à necessária (re)configuração dos processos de trabalho e de apoio. Para isso, foram realizadas atividades de estudo; participação em eventos, cursos, redes; e acompanhamento e troca de experiências com outras instituições, especialmente as internacionais, pois já tinham iniciado sua prática de apoio ao docente nessas circunstâncias extraordinárias, visto que as instituições brasileiras adotaram o ERE posteriormente.

Formação docente - diferentes frentes de formação acompanharam todo o período letivo (Figura 1). Na excepcionalidade trazida pela pandemia, os desafios pedagógicos da docência universitária mostravam-se ainda mais complexos. Os professores precisaram planejar e percorrer uma trajetória integral ou parcialmente desconhecida, reconfigurando constantemente os processos de ensino-aprendizagem no formato de interações síncronas e assíncronas em um ambiente de teletrabalho, com enfrentamento de adversidades que extrapolavam sua formação e experiência. ${ }^{13}$

Como referido, a primeira iniciativa de apoio foi a criação da página do ensino digital e a elaboração de guias e tutoriais (textos e vídeos). No momento, a página, com registro de 25 mil acessos, conta com 102 documentos e 23 links referentes à organização das disciplinas, processo de avaliação, proteção de dados, direito autoral e segurança digital, AVAs e aplicativos, laboratórios remotos e simulações, produção de vídeos, banco de aulas, gravações dos webinários, resoluções institucionais e dos Conselhos de Educa- ção. Nessa oportunidade, além do email, também foi implantado um atendimento online, via chat, com respostas dadas pelos funcionários durante 0 expediente e, fora desse período, com respostas automáticas ou registro das dúvidas para posterior contato. Foram realizados 250 atendimentos online. A página criada mostrou-se muito útil e outras instituições também puderam aproveitar o seu conteúdo. Ela se mantém em atualização constante e vem sendo alimentada de forma colaborativa por meio de contribuições enviadas pela comunidade.

As experiências formativas também se tornaram remotas, com a realização de webinários, lives, rodas de conversa e cursos. Foram realizados 11 webinários entre 30 de abril e 16 de julho de 2020, sobre os seguintes temas relacionados ao ERE: experiências internacionais (Universidade do Minho, Universidade Nacional Autônoma do México, Universidad Tec Monterrey) e da Universidade Virtual do Estado de São Paulo (Univesp), avaliação da aprendizagem, laboratório remoto, licenciaturas, interatividade, engajamento do estudante e docência. No total, foram 1949 participantes neste importante espaço de discussão interna e interinstitucional, especialmente voltado para os momentos iniciais de migração e implantação do ERE.

Outra atividade foram as lives voltadas para a formação no ambiente virtual de aprendizagem Moodle, com a realização de dois encontros e 280 participantes. O primeiro abordou seu funcionamento, apresentando o acesso e uso das ferramentas básicas para o desenvolvimento de uma unidade curricular. E o outro ocupou-se da utilização do Moodle para criar e aplicar avaliações online incluindo: processo de criação de um banco de questões, aplicação de uma prova ou teste online, uso do Safe Exam Browser (SEB) do Moodle como um recurso para restringir o acesso dos estudantes a sites externos, recursos do sistema operacional ou outros aplicativos enquanto eles realizam uma avaliação online.

Destaca-se, também, a iniciativa da Pró -reitoria de Graduação (PRG) com oferecimento de quatro turmas no curso "Estratégias para o ensino remoto", realizado entre os meses de agosto e novembro de 2020, como forma de propiciar escala e agilidade na formação docente 
para o ERE. Foi uma prestação de serviço para apoiar as ações institucionais, com participação próxima da equipe da PRG em seu planejamento e realização, de forma a atender a realidade dos cursos de graduação da Unicamp. O curso foi estruturado em quatro módulos, sendo que cada um contava com um momento síncrono e atividades assíncronas com tarefas práticas e discussão em fórum. Ademais, eram disponibilizados na plataforma do curso, materiais de estudo e aprofundamento em diferentes formatos (texto, podcast, videoaula). De forma integrada e envolvendo a vivência de diferentes recursos e ferramentas online, foram abordados os seguintes tópicos: desafios do ERE, especificidades do planejamento de disciplina para o ensino remoto, interatividade, engajamento dos estudantes, trabalho em grupo colaborativo, sala de aula invertida, Google Classroom e estratégias de segurança no ambiente virtual. Houve a participação de 341 professores. Em outro curso, com presença de 75 coordenadores de curso, membros de comissões de graduação ou núcleo docente estruturante, foram tratados os temas de projeto pedagógico de curso, inovação curricular e atividades acadêmicas de extensão. Também foram oferecidas 297 vagas no programa de desenvolvimento para a docência por meio do Consórcio STHEM Brasil, distribuídas nos cursos Problem Based-Learning - PBL (Aprendizagem Baseada em Problemas), Peer Instruction (Instrução entre Pares), Flipped Classroom (Sala de Aula Invertida) e Team Based Learning (Aprendizagem em Equipe).

Outra importante frente de atuação se deu por meio da criação da Comunidade de Prática Ferramentas Digitais para Apoio à Docência, em junho de 2020, com o objetivo de reunir professores universitários interessados em discutir o uso de tecnologias educacionais, de forma prática, teórica e socialmente compartilhada, sobre como e quando usá-las, no intuito do aprimoramento do processo de ensino e aprendizagem e desenvolvimento profissional docente. Envolve a interação entre os participantes, para estudos, demonstrações, tutoriais e troca de experiências, com a utilização de ferramentas digitais para comunicação e colaboração online. As rotas de aprendizagens são propostas conforme o interesse do grupo e realizadas individualmente no tempo e sequência definida pelo participante. Até o momento foram organizadas seis rotas e 12 fóruns de discussão, a respeito dos temas: Ferramentas Digitais Assíncronas (Usando o Fórum como ferramenta de Ensino, Google Suite, Captura e Edição de Vídeos, Introdução ao uso do Prezi) e Estratégias de Aprendizagem (Criando Rotas/Roteiros de Aprendizagem, Engajamento Estudantil). Somam, nessa ocasião, 53 participantes na plataforma.

Decorrente da experiência com os webinários e visando não só o desenvolvimento profissional docente por si, mas também, um espaço para discussão aberta e coletiva sobre o vivido e o sentido, entendeu-se que seria importante propor um espaço virtual para partilha de experiências, dificuldades, aprendizagens e reflexões sobre os desafios do ERE vivenciados pelos docentes da universidade. Com esse objetivo, desde o final de agosto têm sido realizadas Rodas de Conversa cuja estrutura inclui duas ou três apresentações iniciais de professores sobre um tema norteador como elemento mobilizador da discussão, seguida por debate e compartilhamento entre os participantes. Já foram realizadas 10 Rodas de Conversa, focalizando o ERE nas especificidades das áreas de conhecimento, a atuação em disciplinas do primeiro ano, as demandas da formação de professores e estágio docente. Até então, 31 professores relataram suas experiências no momento inicial de cada Roda de Conversa, com presença aproximada de 385 participantes na atividade.

Apoio aos docentes no (re)planejamento das disciplinas - Atendimento direcionado às demandas dos professores quanto ao delineamento/ajuste pedagógico do plano específico das disciplinas para ERE, otimização da participação dos estudantes, definição de processos de ensino aprendizagem ajustados ao trabalho online. Orientações sobre adaptações aos cursos práticos que possuem experimentação, laboratórios, clínicas e trabalhos de campo, por exemplo, foram no sentido de verificar a viabilidade de utilizar vídeos gravados, laboratórios virtuais ou outras estratégias a fim de substituir essas atividades. A Unicamp também instituiu a possibilidade de adiamento de finalização de disciplinas, permitindo que conteúdos e atividades práticas pudessem ser ministradas em semestre 
posterior, de modo presencial. Esta é uma situação em que a disciplina fica em suspenso até que as atividades sejam executadas.

Considerando que a disrupção não se limitava às decisões quanto aos meios de ensino e acompanhamento de sua implantação, na próxima seção apresentamos uma síntese dos resultados de estudos desenvolvidos com a comunidade da universidade quanto ao impacto das circunstâncias extraordinárias.

\section{CONHECENDO O DOCENTE DA UNI- CAMP E SUAS CONDIÇÕES DE TELE- TRABALHO}

O domínio das tecnologias, confiança, autonomia, competência digital ${ }^{14}$ e o acesso a equi- pamentos e internet foi diversificado entre os docentes e estudantes. Mas também a concepção de ensino e aprendizagem e a abertura para mudança exigida pelo ERE adotado.

Houve um grande esforço na Unicamp para conhecer as diversas implicações causadas pela situação de pandemia no trabalho e na saúde mental do docente. Internamente foram conduzidos diversos levantamentos institucionais, sendo a pesquisa realizada pelo Observatório Institucional da UNICAMP (OIU) aquela de maior abrangência de temas e participação da comunidade. ${ }^{15}$

Entre junho e julho de 2020, 885 docentes responderam ao questionário. Foram identificados diversos pontos importantes apontando para um diagnóstico do panorama conjuntural e que pudessem ser norteadores para tomada de decisões. O Quadro 1 apresenta um compilado de cinco pontos.

Quadro 1: Temas destacados na avaliação "A UNICAMP e o novo Coronavirus: Relatório Docente" 15

\begin{tabular}{ll}
\hline TEMA & SÍNTESE DA ANÁLISE \\
\hline $\begin{array}{l}\text { Uso de ambientes } \\
\text { virtuais de apren- } \\
\text { dizagem e platafor- } \\
\text { mas de videoconfe- } \\
\text { rência (AVA) }\end{array}$ & $\begin{array}{l}\text { Os docentes da Unicamp estão habituados ao uso de AVAs. Essa é } \\
\text { docentes utilizam plataformas como Moodle }\end{array}$ \\
$\begin{array}{l}\text { para o uso do Go G. A facilidade } \\
\text { institucionalmente no ensino, seja para abertura de sala ou para sua } \\
\text { operação, foi importante para inclusão digital de docentes e estudan- } \\
\text { tes. }\end{array}$ \\
$\begin{array}{ll}\text { Acesso à Internet } \\
\text { e equipamentos } \\
\text { computacionais no } \\
\text { home office }\end{array}$ & $\begin{array}{l}\text { Aproximadamente 70\% da comunidade docente teve baixa dificulda- } \\
\text { de em montar sua estrutura de trabalho computacional no teletraba- } \\
\text { Iho. Unidades de Ensino e Pesquisa facultaram o empréstimo de equi- } \\
\text { pamentos aos docentes a fim de melhorar as condições de trabalho. }\end{array}$ \\
\hline $\begin{array}{l}\text { Domínio do uso de } \\
\text { tecnologias digitais }\end{array}$ & $\begin{array}{l}\text { Metade dos docentes alegaram ter domínio das tecnologias digitais } \\
\text { para realizar o ensino remoto; cerca de 40\% respondeu que não } \\
\text { precisou de nenhum auxílio para continuar suas atividades de ensino. }\end{array}$ \\
$\begin{array}{l}\text { Esse é um dado importante e provavelmente tenha relação com a } \\
\text { renovação do quadro docente em curso na última década. }\end{array}$ \\
$\begin{array}{l}\text { Os dois maiores desafios citados pela comunidade foram relaciona- } \\
\text { Desafios do ensino } \\
\text { remoto }\end{array}$ & $\begin{array}{l}\text { dos à aplicação de avaliações e à falta de convívio e interação com } \\
\text { estudantes. }\end{array}$ \\
\hline $\begin{array}{l}\text { Andamento das } \\
\text { atividades durante } \\
\text { o ERE }\end{array}$ & $\begin{array}{l}\text { Nesse ponto observa-se um equilíbrio entre aqueles que acreditam } \\
\text { que seu desempenho nas aulas piorou no ERE e outros que acham } \\
\text { que está melhor ou igual ao período presencial. Esse dado inconclusi- } \\
\text { vo talvez indique ainda o regime de transição/adaptação e os efeitos } \\
\text { da expectativa de retornar ao modo presencial no final do 1o semes- } \\
\text { tre de 2020 - o que obviamente não ocorreu. }\end{array}$ \\
\hline
\end{tabular}


Em uma enquete conduzida pela Associação de Docentes da Unicamp (Adunicamp), o foco ficou restrito ao docente e suas condições de trabalho remoto. ${ }^{16} \mathrm{~A}$ coleta de dados foi realizada em maio de 2020 e foi respondida por 400 docentes associados que atuam em diferentes áreas do conhecimento, de diferentes faixas etárias, organizada em sete eixos. Destes, iremos destacar somente quatro: (i) Eixo 3 - Condições gerais de trabalho remoto na Universidade; (ii) Eixo 4 - Cotidiano do ensino remoto na Universidade; (iii) Eixo 5 - Impactos institucionais do uso mais sistemático e constante de novas TICs no trabalho docente na Universidade; (iv) Eixo 6 - Dificuldades e aprendizados no contexto de ensino remoto na Universidade.

Pouco mais de $50 \%$ dos docentes que responderam acreditavam ter havido aumento de trabalho dedicado ao ensino. Este é um dado que denota claramente um processo de preparação e adaptação das disciplinas a um novo tipo de ambiente, virtual, utilizando-se de novos recursos. Esse dado é coerente com um dos aspectos abordados no Eixo 4, o tipo de atividade de ensino adotada pelo docente, sendo que cerca de $45 \%$ utilizou aulas gravadas e quase $50 \%$, recursos de AVAs e TICs como podcast. Estes elementos nem sempre estão no rol de atividades na modalidade de ensino presencial, mas passaram a fazer parte do cotidiano do trabalho/ensino remoto. Ainda nesse Eixo, importante destacar que as respostas docentes indicaram que eles passaram a usar de forma sistemática recursos como salas de videoconferência (Google Meet), Moodle ${ }^{T M}$, GCR e softwares de gravação de voz.

Acerca do Eixo 5, destaca-se a possibilidade de uso de ensino híbrido, ou ensino à distância, mesmo após o término da pandemia para $65 \%$ dos docentes. Isso, de certa forma, revela um empoderamento docente quanto ao uso de TICs e da percepção de qualidade positiva da complementariedade dos recursos digitais, permitindo uma proposta de ensino híbrido. Finalmente, a pesquisa Adunicamp apresenta as preocupações dos docentes quanto ao aprendizado e dificuldades no contexto do ensino remoto. Algumas preocupações emergiram deste grupo de respondentes refletindo certo desconhecimento sobre o ensino a distância, ensino remoto, e também a forma abrupta de migração para o ERE. Manifestaram preocupação com a qualidade da aprendizagem, interação com estudantes, dúvidas sobre a avaliação e acompanhamento de estudantes, e temor pela precarização do ensino e falta de competências digitais dos docentes. ${ }^{16}$ Importante destacar que questões sobre qualidade de ensino a distância são pontos amplamente discutidos na literatura da área, não havendo evidência de menor qualidade quando os princípios educacionais são respeitados. ${ }^{17,18}$

Fica patente nos levantamentos realizados, a importância da competência digital do docente, entendida como a capacidade de compreender e utilizar os recursos de tecnologia de informação e comunicação (TIC) no trabalho, no ensino e na aprendizagem. Em conjunto com a METAREDE uma rede internacional de cooperação acadêmica na área de TI e o Joint Research Center (JRC), um centro de pesquisa da União Europeia -, a Unicamp realizou uma avaliação sobre as competências digitais dos docentes entre outubro e novembro de 2020. Trata-se de um processo de auto-avaliação que inclui a análise de 21 competências organizadas em seis áreas: engajamento profissional, recursos digitais, ensino e aprendizagem, empoderamento dos alunos, avaliação e apoio ao desenvolvimento digital dos alunos. ${ }^{19}$ Cerca de 300 docentes preencheram o questionário de avaliação e os resultados devem ser divulgados em março próximo.

\section{CONSIDERAÇÕES FINAIS}

A Universidade foi extremamente desafiada com a pandemia Covid-1920,21 e tem aprendido muito sobre equidade, flexibilidade, apoio, proximidade e agilidade das decisões e processos. As estruturas de apoio ao ensino e à formação, então existentes, possibilitaram um rápido avanço no enfrentamento deste momento de dificuldades sem precedentes, que geraram tanta apreensão e incertezas. Mesmo assim, e também diante do seu prolongamento muito além do tempo estimado, tem sido um processo muito exigente a toda comunidade e órgãos da Unicamp, que vem respondendo com intenso engajamento, disponibilidade e esforço para a reinvenção que tem 
sido constantemente necessária. As concepções sobre a docência universitária passaram a ser fortemente debatidas no interior da universidade, assim como, os projetos pedagógicos dos cursos e o papel dos componentes curriculares na formação dos estudantes. Ao explorar novas práticas, buscar ajuda, cooperar, expor resistências, compartilhar experiências, textos, aplicativos, dentre outras, o ensino e a aprendizagem ganharam importante centralidade no interior da universidade. Concebe-se, desta forma, a força da universidade nesse tempo de enfrentamento individual e coletivo como oportunidade para significativas mudanças no cotidiano acadêmico e universitário, na docência, no papel das relações afetivas, seja quanto aos novos desafios que se colocam como àqueles velhos conhecidos, escancarados/intensificados com a pandemia.

Assim como havia a convicção, desde o início, que a Unicamp poderia dar uma resposta acadêmica e institucional à altura dos desafios que se colocavam, também inferimos sua condição de assegurar uma formação de excelência na gestão desta(s) crise(s) que ainda estaremos envolvidos por tempo indeterminado, seja pela presença, ação e propagação do vírus, como pelo impacto causado, cuja projeção de superação deve ser longa. Parafraseando Pacheco ${ }^{21}$, as universidades "[as escolas] são surpreendentes no modo como lidam com realidades extraordinárias e [que a] sua resiliência é um aspeto bastante positivo para este tempo difícil, que exige soluções urgentes e adequadas". Essa mesma potência é trazida por Mendes, Pletsch e Lockmann ${ }^{22}$ ao apresentar a seção temática "Adiando o fim da escola: perspectivas internacionais sobre Educação em tempos de pandemia", publicada pela Revista Práxis Educativa. De modo pontual, Ferigato, Teixeira, Fragelli23 indicam a seguinte agenda para a reconstrução da educação brasileira: "democratização do acesso à internet, a qualificação dos docentes e estudantes para o uso de tecnologias digitais, a garantia de acesso a essas tecnologias, bem como a preservação dos direitos trabalhistas de educadores na era da cibercultura e da hibridização das práticas educacionais e temas estruturais - como o racismo, o machismo e a desigualdade social" (p. 11).

De modo particular, os centros de formação docente terão importante responsabilidade neste contexto. E, desde que acadêmica e coletivamente consideradas, as transformações decorrentes deste período, que tão fortemente tem repercutido no cotidiano da universidade e das pessoas, poderão dar sustentação e inspiração para o pós-covid, aprimorando o desenvolvimento profissional dos docentes e as ações formativas na graduação. Para isso, seria relevante a maior aproximação e sinergia dos órgãos de apoio ao docente das diferentes instituições no processo de acompanhamento, avaliação e planejamento de suas ações, visando a valorização docente e do ensino de graduação.

\section{REFERÊNCIAS}

1. Organização das Nações Unidas para a Educação, a Ciência e a Cultura. Adverse consequences of school closures. [Internet] 2020. Paris: UNESCO, 2020. Available from: https://en.unesco.org/covid19/educationresponse/consequences

2. Fundação Oswaldo Cruz. ConVid: Pesquisa de Comportamentos - Adultos. 2020 [Internet]. Rio de Janeiro: FIOCRUZ, 2020. [cited 2021 Jan 20]. Available from: https://convid.fiocruz.br/index.php?pag=apresentacao resultadoFunda

3. Amaral, E, Polydoro, S. Os desafios da mudança para o ensino remoto emergencial na graduação na Unicamp - Brasil. Linha Mestra [Internet], 2021 [cited 2021 Jan 20]; 41(A); 2021:19809026. Available from: https:// doi.org/10.34112/1980-9026a2020n41ap52-62

4. Da Cunha MI. Docência na Educação Superior: a professoralidade em construção. Educação (Porto Alegre) [Internet].2018 [cited 2021 Feb 17]; 41(1). Available from: https://revistaseletronicas.pucrs.br/ojs/index. $\mathrm{php} /$ faced/article/view/29725

5. De Almeida MI, Pimenta SG. Pedagogia universitária Valorizando o ensino e a docência na universidade. RPE [Internet]. 2014 [cited 2021 Feb 21]; 27(2). Available from: https://revistas.rcaap.pt/rpe/article/view/6243

6. Masseto MT. Competência Pedagógica do Professor Universitário. 3.ed. São Paulo: Summus; 2015. 207p.

7. Zabalza MA, Beraza S, Alfonso C, Alonso, FT. Formación docente del profesorado universitario: el difícil tránsito a los enfoques institucionales revista española de pedagogía. [Internet] 2020. Rev. Esp. Pedag. LXXII, [cited 2020 Jul. 24];257;2014. Available from: https://revistadepedagogia.org/wp-content/uploads/2014/02/257-03.pdf

8. Hornink GG, Vieira F, Costa M J. O papel do Centro IDEA-UMinho na transição para o ensino online durante a pandemia COVID-19: enfrentar desafios e criar oportunidades (Re)Ações [Internet] 2020 [cited 2020 Dec. 20]; 2020:21814. Available from: https://doi.org/10.21814/ uminho.ed.24.8 
9. Hodges C, Moore S, Lockee B, Trust T, Bond A. The difference between emergency remote teaching and online learning Friday. EDUCAUSE Review. [Internet]. 2020 [cited 2020 Jul. 24];27;2020. Available from: https:// er.educause.edu/articles/2020/3/the-difference-between-emergency-remote-teaching-and-online-learning .

10. Gil AC, Pessoni A.Estratégias para o alcance de objetivos afetivos no ensino remoto. Rev. Docência Ens. Sup. (Belo Horizonte) [Internet]. 2020 [cited 2021 Jan 28]; 10; 2020:24738 Available from: https://doi. org/10.35699/2237-5864.2020.24493

11. O'Keefe L, Rafferty J, Gunder A, Vignare K. Delivering high-quality instruction online in response to COVID-19: Faculty playbook. Every Learner Everywhere, 2020. [cited 2020 Jun. 20] Available from: http://www.everylearnereverywhere.org/resources.

12. Osório AJ. Reflexões sobre tecnologia e educação em tempo de pandemia. (Re)Ações. [Internet] 2020 [cited 2020 Dec. 20]; 2020:21814. Available from: https:// doi.org/10.21814/uminho.ed.24.9

13. Fior, CA, Martins, MJ. A docência universitária no contexto de pandemia e o ingresso no ensino superior. Rev. Docência Ens. Sup. (Belo Horizonte). [Internet]. 2020 [cited 2021 Dec. 29];10; 2020:24742 Available from https://doi.org/10.35699/2237-5864.2020.24742

14. Redecker C.European Framework for the Digital Competence of Educators: DigCompEdu. EU SCIENCE HUB. [Internet] 2020 [cited 2020 Dec. 20] Available from: https://ec.europa.eu/jrc/en/publication/eur-scientific-and-technical-research-reports/european-frameworkdigital-competence-educators-digcompedu

15. Observatório Institucional Unicamp. A Unicamp e o novo Coronavírus: relatório docente 2020. [Internet]. Campinas: OIU, 2020. [cited 2021 Jan 21]. Available from: https:// www.observatorio.cgu.unicamp.br/paginas/relatorios.

16. Associação de Docentes da Unicamp. Condições de trabalho remoto docente na Unicamp no contexto da pandemia de Covid-19 - 2020 [Internet]. Campinas: ADUNICAMP, 2020. [cited 2021 Jan 21]. Available from: http://adunicamp.org.br/novosite/adunicamp-apresenta-o-relatorio-da-consulta-sobre-as-condicoes-detrabalho-docente-remoto-durante-a-pandemia-de-covid-19/

17. International Council For Open And Distance Education. Global quality in online, open, flexible and technology enhanced education: An analysis of strengths, weaknesses, opportunities and threats - 2019. [Internet]. Oslo: ICDE, 2019. [cited 2021 Jan 20]. Available from: https://www.icde.org/knowledge-hub/report-globalquality-in-online-education. Acesso em: 20 jan. 2021.

18. Bielschowsky, CE. Qualidade na Educação Superior a Distância no Brasil: onde estamos, para onde vamos? EaD Em Foco [Internet]. 2018 [cited 2021 Jan 21]; 8(1); 2018:eadf.v8i1.709. Available from: http://dx. doi.org/10.18264/eadf.v8i1.709

19. Lucas M, Moreira A. DigCompEdu: quadro europeu de competência digital para educadores. Aveiro: UA Editora; 2018.

20. Crawford, J., Butler-Henderson, K., Jurgen, R. Malkawi, B. H.; Glowatz, M.; Burton, R.; Magni, P.; Lam, S. COVID-19: 20 Countries' Higher Education Intra-Period Digital Pedagogy Responses. Journal of Applied Teaching and Learning (JALT) [Internet]. 2020., 3(1) 9-28. Available from: https://doi.org/10.37074/jalt.2020.3.1.7

21. Pacheco JA. Uma outra escola? Público. [Internet] 2020 [cited 2020 Dec. 20] Available from: www.publico. pt/2020/04/07/impar/opiniao/escola-1911167

22. Mendes GML, Pletsch MD, Lockmann K. Adiando o fim da escola: perspectivas internacionais sobre educação em tempos de pandemia. Práxis Educativa [Internet] 2020 [cited 2020 Dec. 20];2020:123105. Available from: https://doi.org/10.5212/PraxEduc.v.15.17127.105

23. Ferigato $\mathrm{SH}$, Teixeira RR, Fragelli $\mathrm{MCB}$. A universidade $\mathrm{e}$ a atividade docente: desafios em uma experiência pandêmica. Rev. Docência Ens. Sup.(Belo Horizonte) [Internet]. 2020 [cited 2021 Dec. 29];10; 2020. Available from: https://periodicos.ufmg.br/indonvid.fiocruz.br/ index.php?pag=principal 
Todos os autores contribuíram igualmente em todas as etapas deste trabalho.

Autor Correspondente:

Soely A. J. Polydoro

soelypolydoro@gmail.com

Editor:

Prof. Dr. Marcelo Riberto

Recebido: 26/02/2021

Aprovado: $13 / 07 / 2021$ 